\title{
Utilising Game Design to Create Engaging Education
}

\author{
A framework for Gameful Learning \\ David Williams \\ ICT Faculty \\ Dublin Business School \\ Dublin, Ireland. \\ david.williams@dbs.ie
}

\begin{abstract}
If educators were to be skilled game designers, then they would be better equipped to design engaging education scenarios. This research engages in studying commercial design of engagement in games, so educators may be able to better facilitate engaging educational design, facilitated through quantified engagement metrics (SCEQ) and game design principles (GameFlow).
\end{abstract}

\section{CCS CONCEPTS}

- CCS Concept: Social and professional topics $\rightarrow$ Student assessment

- CCS Concept: Applied computing $\rightarrow$ Education

\section{KEYWORDS}

ACM proceedings; Education; Framework; Gamification; Game Development; Flow; MDA; Pedagogy; Engagement.

\section{ACM Reference format:}

David Williams. 2019. Utilising Game Design to Create Engaging Education: A framework for Gameful Learning. In Proceedings of Annual Conference on Innovation and Technology in Computer Science Education of ACM Annual SIG Conference (ITiCSE'19), July 15-17, 2019, Aberdeen, Scotland Uk. https://doi.org/10.1145/3304221.3325594

\section{CONTEXT AND MOTIVATION}

In commercial game design, player engagement if a key factor for measuring success. Identified on occasion as flow [1], the balance between tedium and frustration. The games industry has become heavily dissected by academia in the search to find relatable methods to increase learner engagement [2]. Thus far however there is a visible disparity between industry standards and academic approaches.

Considering the gaming element of rewards for example, an often misunderstood concept, if we recognise that not all students

Permission to make digital or hard copies of part or all of this work for personal or classroom use is granted without fee provided that copies are not made or distributed for profit or commercial advantage and that copies bear this notice and the full citation on the first page. Copyrights for third-party components of this work must be honored. For all other uses, contact the Owner/Author.

ITiCSE '19, July 15-17, 2019, Aberdeen, Scotland Uk

(C) 2019 Copyright is held by the author. Publication rights licensed to ACM. ACM ISBN 978-1-4503-6301-3/19/07.

https://doi.org/10.1145/3304221.3325594 are motivated by the same rewards [3]. The games industry has identified the potential negative influence of points or scores and have adapted to eliminate these as the focus of a lot of titles [4]. A fundamental principle of this research is that a focus on ludology [5] and game design principles as a tool for building are essential. Current research into games is based on dissecting games the medium to understand the principles of what make them effective [6]-[8]. Yet the game developers are using principles of game design as the method to construct their products from the first iteration. It is proposed that instead of deconstructed games, educational design would benefit from creating their material from the game design principles. This research is grounded in this approach, providing measurable outcomes in response to create a gameful engagement scenario.

\section{LITERATURE REVIEW}

Viewing education as a journey with knowledge as the destination, would be comparable to the experience of a game, exams and practical are game challenges, learning outcomes are win conditions, and as in games the aim is to change the player/learner over the journey.

It has been thoroughly studied as to why students may want to learn. In adult learning or andragogy for example it is proposed that adult learners learn due to two intrinsic factors. They want to or they need to [9], motivation is a key factor for engagement in education. This is true in the field of videogame development as to what makes a player want to play a game [10]-[12]. As such there is growing interest in the means to leverage motivational methods used in videogames within education.

A core challenge facing this transfer of motivational methods is that games, although natural learning environments fail once they no longer feel like a game [13]. The idea that a game must feel like a game [14] is not new and a lack of understanding in attempting to implement games scenarios without the core knowledge of game design can result in a contrived game environment, as most game designers will state that the game is not the experience, but rather the means to achieve the experience.

Gee and Hayes [15], who have also stated that although there is a current popular desire to allow students to develop without guidance, that this can allow students to get misdirected into answering the wrong questions, where they may find good answers, it is the role of the educator to direct the learning, as it is the role of the game designer to make sure the player finds the end 
of the game and completes a journey. In recent years many researchers have investigated potential frameworks for implementing gameful learning scenarios [16], [17] with many focusing on the impact these designs have on participant engagement. In game design, MDA [18] is an iterative approach to design and tuning, allowing game designers to anticipate how changes will impact each aspect of development within the framework and the resulting implementations.

\section{HYPOTHESIS}

This study is an investigation of the potential for educators to leverage game design mechanisms, proposing that educators would then be better equipped in designing engaging education. Subsequently this research aims to offer a framework for designing educational scenarios, based around a core principle: we must stop being educators dissecting and borrowing game elements, but rather that we are game designers building educational scenarios by mapping engagement using established game development formats like that of Mechanics, Dynamics \& Aesthetics (MDA) [19]. and Flow [20] to established engagement metrics such as the Student Course Engagement Questionnaire (SCEQ) [21] providing a quantifiable outcome for use in class design.

\section{RESEARCH GOALS}

The primary research goal is to develop a practical framework for designing engaging classroom content that can be measured. To achieve this, secondary research goals were undertaken.

This was firstly approached by identifying appropriate game design mechanisms to apply to classroom design strategies. Whilst examining learning environments to identify measures of engagement, testing unobtrusive and unbiased observation methods of monitoring. Secondly the quantifying and approximating engagement metrics were evaluated and aligned with game design principles in live learning environment. Finally aspiring to derive scenarios where the framework could enhance, extend and improve student engagement though the application of design principles.

\section{RESEARCH METHODS}

The SCEQ [21] was administered, as an observational nonmanipulative design, to undergraduate students in semester 1 . Data was collected for the last 6 weeks of the first semester for all enrolled students.

Examining a sample snapshot of the Students sample in week 1 the Kaiser-Meyer-Olkin measure of sampling adequacy was 0.837 , and the significance of the Bartlett's test of sphericity was $<0.0001$ - these two statistics confirm that the exploratory factor analysis technique was appropriate to use on the data.

In week 2 for the Students the Kaiser-Meyer-Olkin measure of sampling adequacy was 0.778 , and the significance of the Bartlett's test of sphericity was $<0.0001$ confirming that the exploratory factor analysis technique was appropriate. Spearman's Rank Order Correlation for week 1 and 2 is .481 indicating a
Moderate positive relationship. The student focus visibly shifts between weeks, utilising the factor descriptions a higher focus on the Emotional Engagement in week 2 in the first factor.

\section{CONTRIBUTIONS}

In quantifying metrics engagement, a precedent is established to justify altering the gameful scenario through controlled mechanics. It is proposed that in mapping game based heuristics, like that of GameFlow [4] to the engagement metrics a quantifiable design approaches to classroom engagement in achievable.

\section{REFERENCES}

[1] M. Csikszentmihalyi, S. Abuhamdeh, and J. Nakamura, "Flow," in Flow and the Foundations of Positive Psychology: The Collected Works of Mihaly Csikszentmihalyi, 2014

[2] E. Bonsignore, V. Moulder, C. Neustaedter, D. Hansen, K. Kraus, and A Druin, "Design Tactics for Authentic Interactive Fiction: Insights from Alternate Reality Game Designers," Proc. 32nd Annu. ACM Conf. Hum. factors Comput. Syst. - CHI '14, pp. 947-950, 2014.

[3] J. R. Veltsos, "Gamification in the Business Communication Course," Bus. Prof. Commun. Q., vol. 80, no. 2, pp. 194-216, 2017.

[4] P. Sweetser, D. Johnson, A. Ozdowska, and P. Wyeth, "GameFlow heuristics for designing and evaluating real-time strategy games," 2012

[5] J. Raessens, "Playful Identities, or the Ludification of Culture," Games Cult. vol. 1, no. 1, pp. 52-57, 2006.

[6] J. P. Gee, E. Hayes, R. J. Torres, A. Games, K. R. Squire, and K. Salen, "Playing to learn game design skills in a game context," ICLS'08 Proc. 8th Int. Conf. Int. Conf. Learn. Sci. - Vol. 3, vol. 3, pp. 368-374, 2008.

[7] D. Dicheva, C. Dichev, G. Agre, and G. Angelova, "Gamification in Education: A Systematic Mapping Study Gamification in Education: A Systematic Mapping Study," Educ. Technol. Soc., vol. 18, no. June, pp. 7588, 2015.

[8] J. Downs, F. Vetere, S. Howard, and S. Loughnan, "Audience experience in social videogaming: effects of turn expectation and game physicality," $\mathrm{CHI}$ '14 Proc. SIGCHI Conf. Hum. Factors Comput. Syst., pp. 3473-3482, 2014.

[9] M. S. Knowles, "Andragogy in Action: Applying Modern Principles of Adult Learning," WebRef, vol. 56, p. 707, 2003.

[10] N. Lazzaro, "Why We Play Games: Four Keys to More Emotion Without Story," Game Dev. Conf., pp. 1-8, 2004.

[11] M. Tanis and J. Jansz, "Gaming for Different Reasons: What Motivates People to Play a Specific Video Game?," Conf. Pap. -- Int. Commun. Assoc., pp. 1-26, 2008.

[12] J. Hamari, L. Keronen, and K. Alha, "Why do people play games? A review of studies on adoption and use," in Proceedings of the Annual Hawaii International Conference on System Sciences, 2015, vol. 2015-March, pp. 3559-3568.

[13] T. Bissell, Extra Lives why video games matter, First. Random House, 2010.

[14] J. H. Murray, "Toward a Cultural Theory of Gaming: Digital Games and the Co-Evolution of Media, Mind, and Culture," Popular Communication, vol. 4, no. 3. pp. 185-202, 2006.

[15] J. P. Gee and E. R. Hayes, Language and Learning in the Digital Age, First USA: Routledge, 2011.

[16] O. Dele-Ajayi, J. Sanderson, R. Strachan, and A. Pickard, "Learning mathematics through serious games: An engagement framework," Proc. Front. Educ. Conf. FIE, vol. 2016-Novem, 2016.

[17] L. Cooke, "Metatuning: A pedagogical framework for a generative STEM education in game design-based learning," ISEC 2016 - Proc. 6th IEEE Integr. STEM Educ. Conf., pp. 207-214, 2016.

[18] R. Hunicke, M. Leblanc, and R. Zubek, "MDA: A Formal Approach to Game Design and Game Research."

[19] R. Hunicke, Robin; LeBlanc, Marc; Zubek, "MDA: A Formal Approach to Game Design And Game Research," Work. Challenges Game AI, 2004.

[20] M. Csikszentmihalyi, "Flow and the Foundations of Positive Psychology," pp. 21-35, 2014.

[21] M. M. Handelsman, W. L. Briggs, N. Sullivan, and A. Towler, "A Measure of College Student Course Engagement," J. Educ. Res., 2005. 